\title{
Study on Performance Evaluation System of Third Party Logistics Enterprise
}

\author{
Wang Xiaobin \\ School of Economic and Management \\ Shengyang Aerospace University \\ Shengyang China \\ 442685235@qq.com
}

\author{
Liu Chang \\ School of Economic and Management \\ Shengyang Aerospace University \\ Shengyang China \\ 896835136@qq.com
}

\begin{abstract}
With the complication of supply chain management and the development of business out-sourcing trend, third party logistics(TPL) has become an import business model in logistics development.In China, TPL development is still at the phrase of commencement. Under this circumstance, it is necessary to establish an effective and applicable performance evaluation index system, which will help the enterprise to advance its management level and promote the development of TPL enterprises in China.This article first of all review on the background, purpose and significance of the study, research status overseas and domestic and the key research thinking and method. Describes concepts and features of the third party logistics,the content and the need for third party logistics performance evaluation, and presented to the third party logistics performance evaluation methods. And then analyzed the particularities of the third party logistics performance evaluation and design of index system of principles, on this basis established a set of index system framework to measure the third-party logistics enterprise performance, which consists of evaluation of financial performance, customer management performance, internal operation performance and innovation performance.
\end{abstract}

Keywords-TPL enterprise; Performance evaluation; Analytic hierarchy process; Fuzzy comprehensive evaluation

\section{INTRODUCTION}

Since the 1980s, market competition becomes more intense along with the trend of economic globalization and the rapid development of information technology as well as the difference between customer demands. Enterprises generally have been depleted profits source, and logistics were generally considered to be "the third profit source apart from companies lowering material consumption and improving labor productivity outside, so modern logistics industry is emerging in the world-wide, which has experienced decades of development, and now is becoming an important hotspot of global economic development and new economic growth point.

Currently, development level of the third-party logistics in China is still relatively low, the proportion of companies unsatisfied with third-party logistics is up to a half. Enterprises facing a growing number of logistics service providers, are hard to make choices; third-party logistics service covers a wide range, and even many logistics service providers could not make an objective judgment on their overall level. Only to conduct performance evaluation and analysis on third-party logistics enterprises will be able to correctly determine the actual operating level of third-party logistics enterprises, improve the management capacity of enterprises, and thus to increase the overall efficiency of enterprises.

\section{THE CURRENT RESEARCH STATUS HOME AND ABROAD}

\section{A. Evaluation of Third Party Logistics Enterprise Performance Status abroad}

Since the 1980s, Western scholars has conducted indepth research on logistics enterprises performance evaluation. With the acceleration of international integration, evaluation of logistics enterprises has been concerned not only by investors and creditors, but also by the enterprise managers, government, the public, employees, etc.. Especially in recent years, with the rise of third-party logistics in Europe and America, third party logistics enterprises performance evaluation becomes a hot area of research scholars at home and abroad.

\section{B. Evaluation of Third Party Logistics Enterprise Performance Status at home}

In China, the development of logistics enterprises started late relatively; for the performance evaluation of logistics enterprises we are still in the exploratory period, and there is no theoretical model of our own; the performance evaluation of logistics enterprises is basically foreign-based theory, and proposed combined with China's economic situation represented by following views:

Du Yaling conducted third-party logistics enterprises performance evaluation through customer satisfaction, including: cost-effectiveness of logistics services, reliability, cargo intact rate, the degree of rapid response, customer complaint resolution, on-time arrival rate, error rate, the two sides of information communication situations and the implementation of contracts,etc.

Wang from the distribution of goods integrity, responsiveness, customer satisfaction, information delivery accuracy, speed, cargo turnover to conduct third-party logistics enterprise performance evaluation.

Zhang Ying believes third-party logistics enterprise performance evaluation system includes three aspects: functional index, stability index, and operating index. Functional index reflects the achievement of the various added-value chains in third-party logistics enterprise, specifically including six dimensions: transport functions, customer service, distribution function, circulation and processing functions, inventory functions, and 
procurement functions; stability index mainly reflects the possibility of long-term management of third-party logistics companies, specifically including seven dimensions: customer service, profitability, technical strength, corporate cohesion, experience, resilience, and corporate image; operating index reflects the current operating situation of third-party logistics companies .

\section{THE THEORY OF THIRD PARTY LOGISTICS PERFORMANCE EVALUATION}

\section{A. The basic theory}

Enterprise performance evaluation method is theoretical evaluation methods specifically applied in the economic field, which is based on accounting and financial management, by the use of the principle of econometrics and modern analytical techniques to set up process of business analysis; it is a science truly reflects enterprise reality, and predicts the future prospects.

Third party logistics performance evaluation refers to all aspects of the evaluation on the results, efficiency, gain, loss of the third party logistics enterprises, which can be qualitative, or quantitative, or both. It is an afterthought assessment and measurement but also in advance control and guidance on logistics enterprise performance and efficiency, in order to evaluate the completion of scheduled tasks, completion levels, benefits achieved and the price paid.

\section{B. Third Party Logistics Performance Evaluation Methods}

Principal Component s Analysis(PCA). It is first proposed by Hotelling in 1933. Principal component analysis is a multivariate statistical analysis method utilizes the idea of dimension reduction: the multivariate statistical analysis under premise of rare loss of the information that changes many multi-indexs into a few integrated indicators.

Analytic Hierarchy Process. AHP as an evaluation method, has combined qualitative analysis and quantitative analysis; it will mathematicize thinking process of evaluators on complex systems. The basic idea is to break down complex problems by evaluators into several levels and a number of elements, and to compare, judge and calculate between the various elements of the same level.

Fuzzy comprehensive evaluation method. The basic idea is the application of fuzzy linear transformation principle and the principle of maximum membership degree, considering a number of factors affecting the object being evaluated, and making its scientific evaluation. It empirically quantifies fuzziness by means of membership functions, and uses the traditional method of mathematical calculation for processing. Third party logistics performance evaluation involves a number of factors or multiple indicators to be evaluated, hence the evaluators cannot conduct comprehensive evaluation from a single factor but based on a number of factors in order to improve the scientific-ness and accuracy,hence this article uses fuzzy comprehensive evaluation method.

\section{THE CONSTRUCTION OF THIRD PARTY LOGISTICS PERFORMANCE EVALUATION SYSTEM}

\section{A. Design principles Third Party Logistics Performance} Evaluation System

In order to establish an effective evaluation index system of third-party logistics companies, the selection of performance indicators should follow the following principles:

\section{1) Operability principles}

Operability is an important factor in setting performance evaluation system that must be considered; without operability, any scientific, rational, systematic or comprehensive evaluation system is in vain. Here operability is simply more focused on the feasibility of indicator data collected.

2) Combination of quantitative and qualitative indicators principle

Only through qualitative evaluation is insufficient; by quantifying the relevant indicators content can visualize complex problems and reflect the logistics business performance more clearly. In third-party logistics business performance evaluation, some factors are difficult to quantify; without considering the impact of these aspects will lost a comprehensive evaluation, hence a combination of quantitative and qualitative method will establish evaluation index system that quantizes certain index, but also corrects some quantitative index by qualitative indicators.

\section{3) The versatility principle}

Evaluation design should have some degree of versatility, both focus on one aspect of the logistics enterprises performance assessment, but also on the overall performance evaluation of logistics enterprises. Evaluation system should be universal, widely used in third-party logistics companies, and should have a relative stability in the development of the theory and practice.

\section{B. Third Party Logistics Performance Evaluation System}

The so-called evaluation system, which can be understood as from which levels to evaluate performance, and these levels combined together should reflect the overall level of the enterprise the performance. Performance evaluation system framework of TPLs established in this paper.

\section{THIRD PARTY LOGISTICS PERFORMANCE EVALUATION}

Since third-party logistics business performance evaluation is a complex system problem, only from a different perspective to assess will achieve a comprehensive and objective evaluation. Enterprise performance evaluation system established contains both quantitative indicators and qualitative indicators, and the dimensions among quantitative indexes are not the same, while many qualitative indicators are difficult to quantify. So right below the paper has introduced Analytic 
Hierarchy Process to determine the weight of each evaluation index, and then use the fuzzy comprehensive evaluation process with examples to evaluate third-party logistics companies performance .

\section{A. Weight set of Third Party Logistics Performance Evaluation System index}

The so-called weight refers to the share occupied by, or the degree of importance of each indicator elements, as well as their degree of impact on the evaluation of the target throughout the evaluation system. The greater the weight, the greater the relative importance, and vice versa. Determining weighting factor is one of the most critical aspects of evaluation, which can directly affect the outcome of a comprehensive evaluation. How to determine the weighting factor is the core issue in a comprehensive evaluation. In this paper, the author uses Analytic Hierarchy Process (also called "characteristic value method") to determine the weight of evaluation index.

In the systematical engineering approach,one of weight design solutions to multi-objective systematic evaluation or decision-making problems is AHP (Analytic Hierachy Process). AHP has a clear, simple, widely applicable, systematic, and other characteristics.

Constructing hierarchical structure model is a key step in Analytic Hierarchy Process: its success affects completion quality of assessment tasks. Because the hierarchical structure model is a systematic and comprehensive embodiment of Analytic Hierarchy Process.

In the third chapter of this article the author has elaborated on the content of third-party logistics enterprise performance evaluation system: according to the index system settings configuration, the use of AHP thinking, the author has classified the designed index in accordance with the mutual links between them into an orderly hierarchical structure model.

\section{B. Establishment of judgment matrix}

After the establishment of a hierarchical model, relative evaluation method in Analytic Hierarchy Process can be used for pairwise comparison among programs. Analytic Hierarchy Process in determining the weights generally uses pairwise comparison approach. Those can form a matrix will be called the judgment matrix. In the judgment matrix, each element of the matrix represents the relative importance of two indicators corresponding to the top indicators. In traditional AHP, the decision-makers often choose 1-9 scale matrix as standard quantitative method, and its value and meaning of the scale are shown in Table I.

\section{TABLE I PROPORTION VALUES AND THEIR MEANINGS IN 1-9 SCALE}

\begin{tabular}{l|l}
\hline$a_{\mathrm{ij}}$ & Cale value \\
\hline 1 & i factor and $\mathrm{j}$ factor are equally important \\
\hline 3 & i factor is slightly more important than $\mathrm{j}$ factor \\
\hline 5 & i factor is significantly more important than $\mathrm{j}$ factor \\
\hline 7 & i factor is strongly more important than $\mathrm{j}$ factor \\
\hline 9 & i factor is extremely more important than $\mathrm{j}$ factor \\
\hline
\end{tabular}

Note: $2,4,6,8$ are corresponding scaling values between two adjacent of the intermediate state .

Using a scale of 1-9 judgment matrix has the following properties: when $\mathrm{i}=\mathrm{j}, \mathrm{Aij}=1$; when $\mathrm{i} \neq \mathrm{j}, \mathrm{Aij}=1 / \mathrm{Aji}$; when $\mathrm{i}, \mathrm{j}=1,2,3 \ldots \mathrm{n}$, Aij $>0$.

1) Single-level sorting and consistency test

a) Single-level sorting

Single-level sorting, refers to calculating the relative weights between factors (or index) under a single criterion (within a grouping ) in the hierarchical structure model. It is the basis for sorting all indicators hierarchy on one level in terms of importance.

Single-level sorting uses feature vector calculation method, that is to say, to calculate the maximum eigenvalue of judgment matrix and its eigenvectors, the vector component of normalized feature is its corresponding factor (or index) of the relative weights. Weight calculation methods include the sum method, radical method, power method, eigenvalue method and so on;in general, to calculate the maximum eigenvalue of judgment matrix and its corresponding feature vector does not need to pursue higher accuracy, it is because judgment matrix itself has a considerable margin of error; using the value of each factor prioritization given by the level of analytic hierarchy process, it in essence is the expression of a qualitative concept, and can use simple approximation algorithms and methods. Using sum method to calculate the weight vector could follow these steps:

$$
w_{i j}=a_{i j} / \sum_{i=1}^{n} a_{i j}{ }_{\mathrm{i}, \mathrm{j}=1,2, \ldots, \mathrm{n}}
$$

(1) normalize each column vector in judgment matrix; where $\mathrm{i}, \mathrm{j}=1,2, \ldots, \mathrm{n}$

$$
W_{i}=\sum_{j=1}^{n} w_{i j}
$$

$$
\mathrm{i}, \mathrm{j}=1,2, \ldots, \mathrm{n}
$$

(2) Each column will be normalized, and the judgment matrix obtained will be summed by row : where $\mathrm{i}, \mathrm{j}=1,2, \ldots, \mathrm{n}$

(3) $w=\left(w_{1}, w_{2}, \cdots, w_{n}\right)_{\mathrm{T}}$;

$$
\boldsymbol{W}_{i}=\boldsymbol{w}_{i} / \sum_{i=1}^{n} \boldsymbol{w}_{i}
$$

(3) the vector 。 $\circ$ is normalized; where $\mathrm{i}, \mathrm{j}=1,2, \ldots, \mathrm{n}$ 


$$
w=\left(w_{1}, w_{2}, \cdots, w_{n}\right)
$$

$\mathrm{T}$ obtained is the eigenvector.

$$
\lambda_{\max }=\frac{1}{n} \sum_{i=1}^{n} \frac{(A w)_{i}}{w_{i}} \quad \mathrm{i}, \mathrm{j}=1,2, \ldots, \mathrm{n}
$$

(4) calculate approximation $\lambda \max$ of the maximum eigenvalues in judgment matrix where $\mathrm{i}, \mathrm{j}=1,2, \ldots, \mathrm{n}$

b) The consistency test

In calculating the vector sorting, we also need to test for consistency. From the principle of the chromatographic analysis, we know that if the matrix $\mathrm{A}$ has a unique characteristic value $\lambda=\mathrm{n}$, the matrix has a structure called the complete consistency, but in the judgment matrix, transitivity and consistency are not strictly required. But look at human law of cognition, there is some sort of logical law in a correct judgment matrix importance sorting. In reality, intuitive pairwise comparison and judgment will have calculation errors, which will inevitably lead matrix does not have full consistency. When the consistency of judgment matrix deviation is too large, the reliability of this approximation is also questionable. So in practice we require judgment matrix meet the general consistency, and test for judgment matrix consistency. Only by testing it could illustrate the judgment matrix is logically reasonable and we could continue to analyze the results. Steps of consistency test are as follows:

(1) calculat consistency index CI

$\cdots$

Where, $\lambda$ is the greatest characteristic root of $A, n$ is the order of judgment matrix.

(2) find the corresponding average random consistency index Rl, Rl is related to the order of judgment matrix; for 1-9 judgment matrix, Saaty gives Rl comparison table shown in Table

II.

TABLE II. AVERAGE RANDOM CONSISTENCY INDEX VALUE RL (THE CONFIDENCE LEVEL IS 90\%)

\begin{tabular}{c|c|c|c|c|c|c|c|c|c}
\hline $\mathrm{n}$ & 1 & 2 & 3 & 4 & 5 & 6 & 7 & 8 & 9 \\
\hline $\mathrm{RI}$ & 0.00 & 0.00 & 0.58 & 0.90 & 1.12 & 1.24 & 1.32 & 1.41 & 1.45 \\
\hline
\end{tabular}

$$
C R=\frac{C I}{R I}
$$

(3) calculate the consistency ratio CR

When CR $<0.1$, the consistency of judgment matrix is considered as acceptable, i.e. has satisfactory consistency. When $\mathrm{CR}>0.1$, it needs to make appropriate amendments to the judgment matrix, and it has a satisfactory consistency. For the first, second matrix that are always the same, then $\mathrm{CR}=0$.

\section{CONCLUSION}

As an important organizational form of modern logistics, third party logistics in our country gets a lot of attention. In the context of accelerated development of third-party logistics, how to evaluate the performance of third-party logistics companies also become a problem worthy of study. This paper in this context has established a third-party logistics enterprise performance evaluation system and done a preliminary study and research of its comprehensive evaluation methods.

To evaluate on the performance of third-party logistics companies, it not only requires a comprehensive index system but also includes the scientific evaluating method and precise evaluation criteria; the paper carried a certain amount of studies on the first two, but for the evaluation criteria, because of China's party logistics development is still in its infancy, it is in need of further exploration by the business community and theory community; as for classification division of qualitative indicators, it also requires a further study.

\section{REFERENCES}

[1] Zhang Rui. Enterprise Strategic Operating Performance Evaluation Index System $[\mathrm{M}]$. China Financial and Economic Publishing House,2002.2-3, 158-159.

[2] Huo Jiazhen, Sui Minggang, Liu Zhongying. An integrated evaluation of innovative enterprise supply chain performance and its evaluation [J]. Hebei People's Publishing House,2001.21-22.

[3] Fan Chunmei, Xin Ruoming. Review of the status quo of Logistics Performance Evaluation [J]. Logistics Technology, 2004, (9) :1717.

[4] Meng Jianmin. Research on business performance assessment [M]. China Financial and Economic Publishing House,2002.35-36.

[5] Zhang Tao, Wen Xinsan. Business Performance Evaluation [M]. Economic Science Press,2002.160-162.

[6] Qinshou Kang et. Comprehensive Evaluation Principles and Applications [M]. Electronic Industry Press,2003.52-54.

[7] Liu Chunyan, Jiang Yang, Chen Yong. SME Third Party Logistics Performance Evaluation System Construction [J]. New West, 2009, (24) :100-102.

[8] Elten Briggs , Timothy D. Landry , Patricia J.Daughertyc. Investigating the influence of velocity performance on satisfaction with third party logistics service $[\mathrm{J}]$. Industrial Marketing Management, 2010, (39) : 640-649. 